\title{
Simulation at regional level of irrigated wheat and tomato in a Mediterranean environment
}

\author{
M. Rinaldi \& R. Ubaldo \\ CRA - Istituto Sperimentale Agronomico, Italy
}

\begin{abstract}
In Mediterranean countries, where water-limited conditions are frequent, it is important to identify soil and crop management which optimize resources transformation and maximize farmers' return. In this research a seasonal merged with a spatial analysis was simulated with AEGIS/WIN, a Geographic Information Systems (GIS) interface from the DSSAT crop simulation package. The case-study refers to a $1000 \mathrm{~km}^{2}$ area (Southern Italy), characterized by 481 soil samples collected at a regular grid. Durum wheat and processing tomato have been simulated punctual-based using soil and long-term weather data (45 years). The two crops have been compared in the following management scenarios: rainfed and three automatic irrigation levels based on soil water content thresholds. Averages and standard deviations of commercial yield (grain and fruit), seasonal irrigation amount, number and profitability were evaluated as model output. GIS allowed one to visualise the output variables in the soil polygons. The wheat productivity was increased by irrigation of $19 \%$ and no difference occurred among automatic irrigation thresholds. In tomato the irrigation increased the yield by 3 times with respect to rainfed, with no difference among irrigation scenarios. Net return of wheat was higher in rainfed than irrigated scenarios also for the cost of water and the low price of the product. For tomato CAW 50\% resulted in the most profitable scenario. The "soil x climate" interaction (rainfall, temperature and soil water holding capability) influenced the spatial response at regional level, allowing us to identify the area more productive for wheat and tomato.

Keywords: simulation model, durum wheat, processing tomato, irrigation scenarios, soil water content, net return.
\end{abstract}




\section{Introduction}

Water resource allocation at district or basin scale, and environmental impact assessment of agriculture activities are typical issues needing of a decision support system where biophysical processes and human interactions such as adaptive changes of agricultural practice have to be modelled. Crops simulation models should appreciate soil-climate-crop interactions, giving suggestion to stakeholders for a better water allocation, also from an economic point of view. Crop models usually need site specific characteristics such as weather, physical and chemical parameters of soil, water management, and agronomic practices [1] as input data. Applicability of these models can be extended to much broader spatial scales by combining them with a Geographic Information System (GIS) [2-5].

Experiences of application of DSSAT software at spatial scale are reported by Hoongenboom and Thornton [4] that applied GIS to bean, maize and sorghum crop models. Calixte et al [6] developed an Agricultural and Environmental Geographic Information System (AEGIS), which combined DSSAT crop models with GIS to assess the impact of different agricultural practices of Puerto Rico. Georgiev et al [7], Heinemann et al [8], Batchelor et al [9] and Nijbroek et al [10] reported further applications of DSSAT at spatial scale, especially for water requirement estimation.

In previous studies the crop models embedded in DSSAT software have been calibrated and validated for Southern Italy conditions [11-13]: it revealed to be a good tool in simulation of field crops in several soil and climatic conditions; large number of users and the upgrade with user-friendly interface and new applications are further reasons to choose DSSAT software. The seasonal analysis [14] has an economic module that allows an economic evaluation useful to compare management scenarios and geographical areas also from an economic point of view.

In this paper we reported the results of a seasonal and spatial simulation of CERES-Wheat and CROPGRO models for two important field crops in Southern Italy in a large area. The objective of this paper is to apply a GIS-based crop model to compare irrigation strategies in durum wheat and processing tomato, to predict crop yield and economic profitability.

\section{Material and methods}

The "Capitanata" is a plain of about $4000 \mathrm{~km}^{2}$ in South-Eastern Italy, mainly cropped with durum wheat, tomato, sugar beet, olive and grape orchards. Irrigation is managed by a local authority "Consorzio per la Bonifica della Capitanata" of Foggia that distributes irrigation water on demand and at low pressure (2-3 bar) at a large part of the plain $\left(1800 \mathrm{~km}^{2}\right)$. A part of this plain (about $1000 \mathrm{~km}^{2}$ ) has been characterized from pedological and climatic point of view. A large number of soil samples (481) were collected at 0-20 and 20-40 cm depth and 115 soil profiles were examined up to $2.5 \mathrm{~m}$ depth. The main chemical and physical characteristics were recorded (texture, hydrological characteristics, 
nitrogen and phosphorus content, organic matter, bulk density, etc.). Daily climatic data (maximum and minimum temperature, solar radiation and rainfall) derived by eight meteorological stations located in the area and managed by the above reported "Consorzio" (Fig. 1).

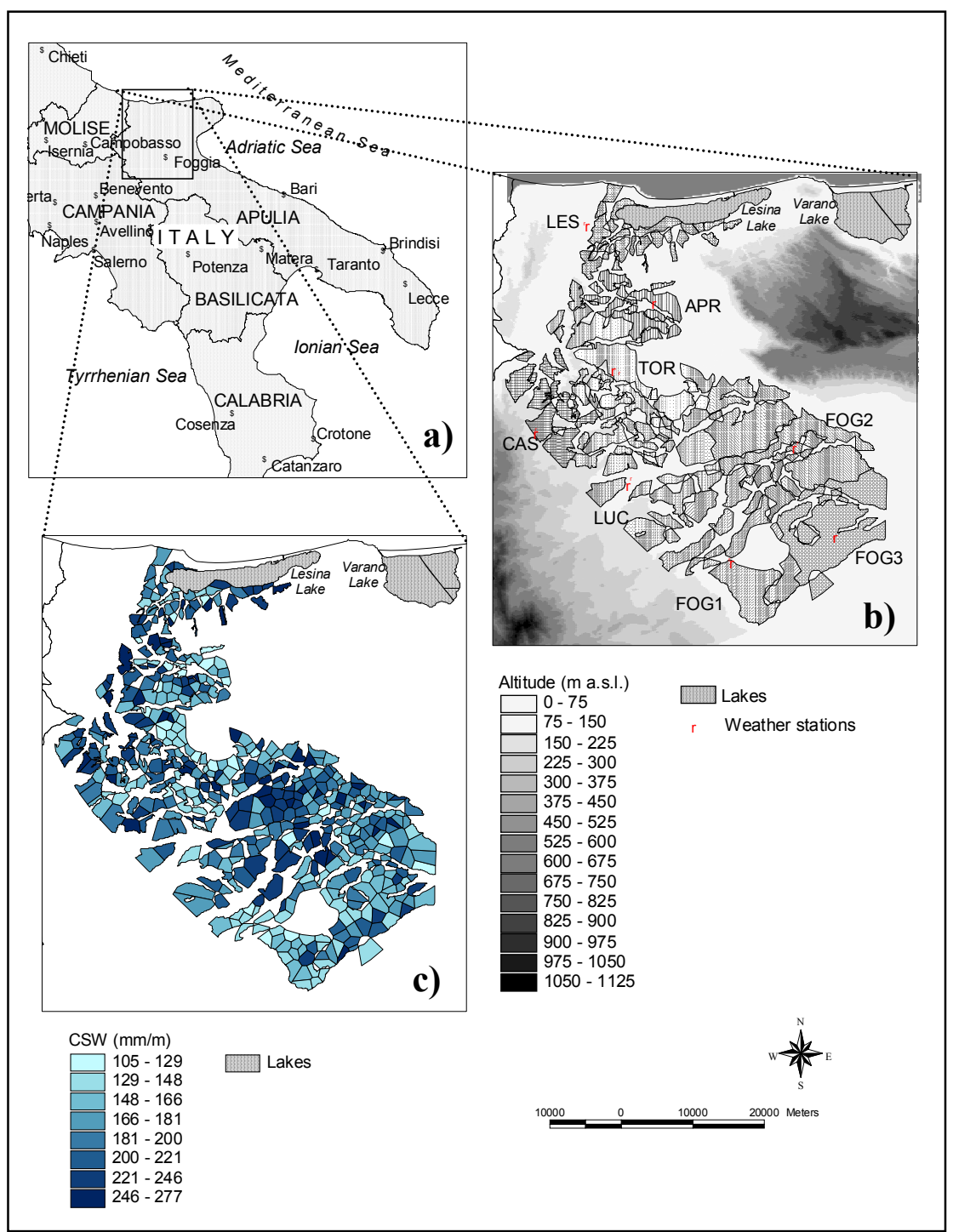

Figure 1: a) Localization of the test area in Southern Italy; b) clustering of the 481 soils round the 8 climatic stations and altitude map of the area as background; c) crop soil water availability $\left(\mathrm{mm} \mathrm{m}^{-1}\right)$ for each soil polygon. 
CERES-Wheat model, embedded in DSSAT program [15], previously calibrated and validated for durum wheat (cv. Simeto) in the test area $[12,16]$ was used in a seasonal (44 cropping cycles, from 1955 to 1999) and spatial analysis comparing the following irrigation scenarios:

1. Rainfed;

2. Automatic irrigation starting at $10 \%$ of crop available water (CAW) in the $0.3 \mathrm{~m}$ soil depth (IRR10), with water amount refilling up to field capacity, until head emission stage; a sprinkler irrigation method was used;

3. Conditions as above at $30 \%$ (IRR30);

4. except at 50\% (IRR50).

The use of low thresholds to start automatic irrigation derive by the fact that in the test area durum wheat is usually not-irrigated or irrigated occasionally (1-2 applications) in the spring. Durum wheat management was simulated with fixed sowing date $\left(15^{\text {th }}\right.$ November), fertilisation with $100 \mathrm{~kg} \mathrm{ha}^{-1}$ of ammonium phosphate pre-sowing and $100 \mathrm{~kg} \mathrm{ha}^{-1}$ of ammonium nitrate at $1^{\text {st }}$ March. Harvest date was simulated by the model at crop maturity.

CROPGRO model, embedded in DSSAT program, has been calibrated and validated in the test area for a processing, self pruning, globe shape, tomato variety (PS 1296 [13]). The simulation was run for the same years and location as before described for wheat, and similarly for the irrigation scenarios, except for thresholds of soil crop available water to start automatic irrigation, fixed for tomato to 30 (IRR30), 50 (IRR50) and 70\% (IRR70).

Tomato crop, according to local management, was simulated with fixed sowing date $\left(30^{\text {th }}\right.$ April), fertilization with $100 \mathrm{~kg} \mathrm{ha}^{-1}$ of ammonium phosphate pre-sowing and $100 \mathrm{~kg} \mathrm{ha}^{-1}$ of ammonium nitrate at fruit formation ( $30^{\text {th }}$ May). Harvest date was simulated by the model at crop maturity.

The 481 referenced points have been converted in polygons using the Thiessen methods (threshold value $=5$ ) and overlaying these polygons with a soil map with pedological characteristics [17]. The interface with a GIS program, AEGIS/WIN, allowed to run the model in the 481 polygons and to display the output of the model using map visualization [18]. The total of run was 21164 for wheat and 21645 for tomato and each polygons represent the average of 44 (45 for tomato) yearly values.

The economic evaluation was performed using seasonal analysis tool, and Net Return (NR) was calculated with prices and costs reported in Table 1. Yield $\left(\mathrm{t} \mathrm{ha}^{-1}\right)$ and net return $\left(€ \mathrm{ha}^{-1}\right)$ for each polygon (soil-climate interaction) were mapped to visualize spatial variability for both crops.

\section{Results and discussion}

The climatic stations are located in plain area: CAS only is placed on a smooth hilly (177 m a.s.1.), while LES is very close to homonym lake and Adriatic sea coast. The coldest and rainiest place is CAS, the warmest are FOG2, FOG3 and LUC; the less rainy locations are FOG1 and FOG3. 
Table 1: $\quad$ Prices and costs of durum wheat and processing tomato field crops in Southern Italy (referred to 2006).

\begin{tabular}{|c|c|c|c|}
\hline Crop & $\begin{array}{l}\text { Operation/product } \\
\text { harvest product }\end{array}$ & Unit & Cost/price \\
\hline \multirow[t]{4}{*}{ Durum wheat } & Grain price & $\left(€ \mathrm{t}^{-1}\right)$ & 160,00 \\
\hline & Base production cost & $\left(€ \mathrm{ha}^{-1}\right)$ & 380,00 \\
\hline & Water irrigation cost & $\left(€ \mathrm{~mm}^{-1}\right)$ & 0,70 \\
\hline & Irrigation application cost & (€/application) & 50,00 \\
\hline \multirow{4}{*}{$\begin{array}{l}\text { Processing } \\
\text { tomato }\end{array}$} & Fresh fruit price & $\left(€ \mathrm{t}^{-1}\right)$ & 60,00 \\
\hline & Base production cost & $\left(€ \mathrm{ha}^{-1}\right)$ & 5500,00 \\
\hline & Water irrigation cost & $\left(€ \mathrm{~mm}^{-1}\right)$ & 1,00 \\
\hline & Irrigation application cost & (€/application) & 15,00 \\
\hline
\end{tabular}

The main difference of 481 polygons derived by the soil texture that influenced the hydrological characteristics (wilting point and field capacity). The crop soil water (CSW, difference between Field capacity and Wilting point), expressed in $\mathrm{mm} \mathrm{m}^{-1}$ of soil depth, is mapped in Fig. 1. A distribution of soils with greater CSW (mainly clay soils) was noticed in the central part of the tested area, close to FOG2 and LUC weather stations, while sandy soils were located in the inner part (FOG1) and close to TOR and APR stations (Fig. 1).

\subsection{Wheat}

Wheat is usually not irrigated in the test area but, in the farms were irrigation sprinkler equipment is available, 1-3 irrigation supplies at sowing and at boot stage are frequent to increase and stabilize grain yield.

The simulation of wheat cropped without irrigation (rainfed scenario) produced an overall mean of $3.0 \mathrm{t}$ of grain yield ha ${ }^{-1}$ (Table 2), with a large variability ranging, at single run simulation level, from 0.3 to $6.4 \mathrm{t} \mathrm{ha}^{-1}$. These simulated values by CERES-Wheat model are not so different by local long-term average. In general, the areas more productive resulted the central and northern parts, the less yielding the southern one (FOG1 and FOG3) (Fig. 2).

The application of automatic irrigation reduced the variability of grain yield (on average coefficient of variation decreased from 43 to 33\%) and increased the grain yield on average of $19 \%$ respect to rainfed scenario $\left(+0.58 \mathrm{t} \mathrm{ha}^{-1}\right)$ (Table 2). The effect of irrigation was not different among the three threshold levels of CAW, showing a parity of yield, despite a difference of seasonal irrigation volume was observed.

The explanation of this result comes from the examination of water balance component: the only one that changed was the crop available soil water at harvest, meaning that the latest irrigation supplies were not used completely by the crop and remained in the soil. This is a normal risk in irrigation practice, when rain events following the irrigation, make vain the irrigation supply. 
The re-initializing of soil condition at every starting date of simulation (two days before sowing) did not allow to one consider this beneficial effect of the previous year.

Table 2: Yield, irrigation and economic results (averages \pm standard deviations) of the CERES-Wheat and CROPGRO models, referred to the 481 soils and to the 44 (45 for tomato) simulated years.

\begin{tabular}{|c|c|c|c|c|}
\hline \multicolumn{5}{|c|}{ Durum wheat } \\
\hline Scenario & $\begin{array}{l}\text { Grain yield } \\
\qquad\left(\mathrm{t} \mathrm{ha}^{-1}\right)\end{array}$ & $\begin{array}{c}\text { Seasonal } \\
\text { irrigation } \\
\text { volume } \\
(\mathrm{mm})\end{array}$ & $\begin{array}{c}\text { Irrigation } \\
\text { applications } \\
\text { (n.) }\end{array}$ & $\begin{array}{l}\text { Net return } \\
\left(€ \mathrm{ha}^{-1}\right)\end{array}$ \\
\hline Rainfed & $3.03 \pm 1.30$ & - & - & $105 \pm 207$ \\
\hline IRR10 & $3.57 \pm 1.18$ & $138.5 \pm 72.4$ & $2 \pm 1$ & $-11 \pm 172$ \\
\hline IRR30 & $3.64 \pm 1.18$ & $183.0 \pm 73.1$ & $3 \pm 1$ & $-94 \pm 171$ \\
\hline IRR50 & $3.62 \pm 1.18$ & $208.8 \pm 71.9$ & $5 \pm 2$ & $-193 \pm 188$ \\
\hline \multicolumn{5}{|c|}{ Processing tomato } \\
\hline Scenario & $\begin{array}{c}\text { Fresh fruit } \\
\text { yield } \\
\left(\mathrm{t} \mathrm{ha}^{-1}\right)\end{array}$ & $\begin{array}{c}\text { Seasonal } \\
\text { irrigation } \\
\text { volume } \\
(\mathrm{mm})\end{array}$ & $\begin{array}{c}\text { Irrigation } \\
\text { applications } \\
\text { (n.) }\end{array}$ & $\begin{array}{l}\text { Net return } \\
\left(€ \mathrm{ha}^{-1}\right)\end{array}$ \\
\hline Rainfed & $54.3 \pm 39.3$ & - & - & $-2374 \pm 2357$ \\
\hline IRR30 & $187.1 \pm 28.1$ & $298.6 \pm 76.8$ & $6 \pm 2$ & $5214 \pm 1685$ \\
\hline IRR50 & $198.0 \pm 25.9$ & $342.8 \pm 79.5$ & $9 \pm 2$ & $5778 \pm 1556$ \\
\hline IRR70 & $197.4 \pm 27.0$ & $398.2 \pm 76.7$ & $15 \pm 4$ & $5597 \pm 1621$ \\
\hline
\end{tabular}

Economic evaluation pointed out the low profitability and the high economic risk of durum wheat crop both in the rainfed scenario and in the irrigated ones. The overall mean of expected net return (NR) resulted negative in the irrigated thesis, decreasing inversely with the CAW threshold values (Table 2). Moreover, a large variability of NR was observed, mainly in the rainfed scenario, more affected by the yearly variability of rainfall. Negative NR values were registered in about $50 \%$ of the soils for the irrigation scheduling IRR 10 ; the number of soils for which irrigation resulted disadvantageous in economical terms increased for IRR30 and concerned the whole test area for IRR50 (Fig. 3). So the results of simulation showed the little increase in grain yield and stability due to irrigation but also highlighted the high incidence of irrigation cost on the global crop management cost. Nevertheless, negative values of NR were observed also in more than 50 soils in the rainfed scenario, mainly located in the southern part of the area, resulted the less productive. 


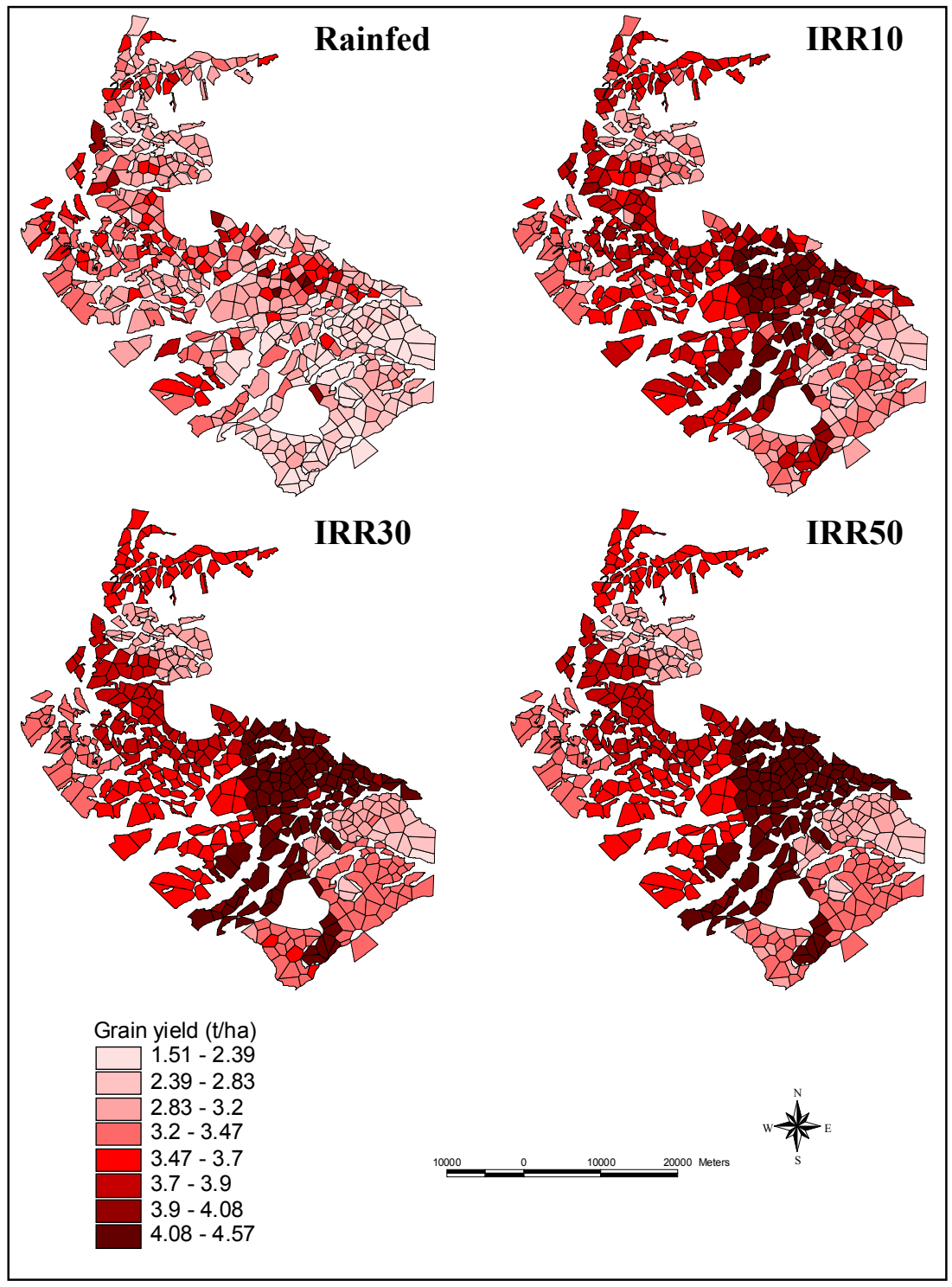

Figure 2: Grain yield ( $\left.\mathrm{t} \mathrm{ha}^{-1}\right)$ of durum wheat simulated by CERES-Wheat model in the four irrigation scenarios and mapped for the 481 soil polygons. 


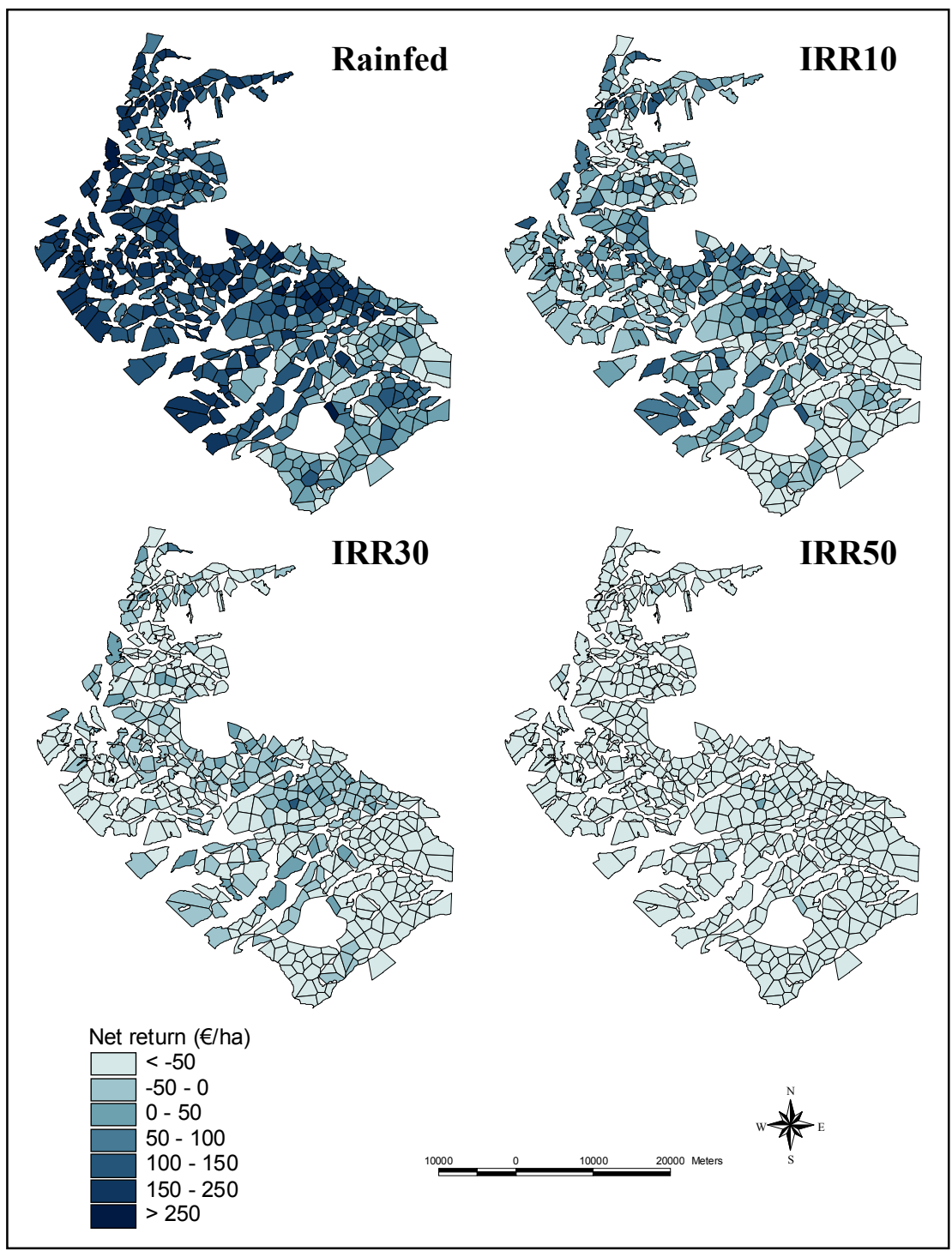

Figure 3: $\quad$ Net return $\left(€ \mathrm{ha}^{-1}\right)$ of durum wheat simulated by CERES-Wheat model in the four irrigation scenarios and mapped for the 481 soil polygons.

\subsection{Tomato}

Tomato crop is usually irrigated in test area, with sprinkler and, more widely, with drip irrigation methods; seasonal irrigation volumes range between 300 and $500 \mathrm{~mm}$. In this simulation activity, the seasonal irrigation volume ranged from 
300 to $400 \mathrm{~mm}$ in the three irrigation scenarios (Table 2), but we choose low CAW thresholds with the specific aim to reduce water application.

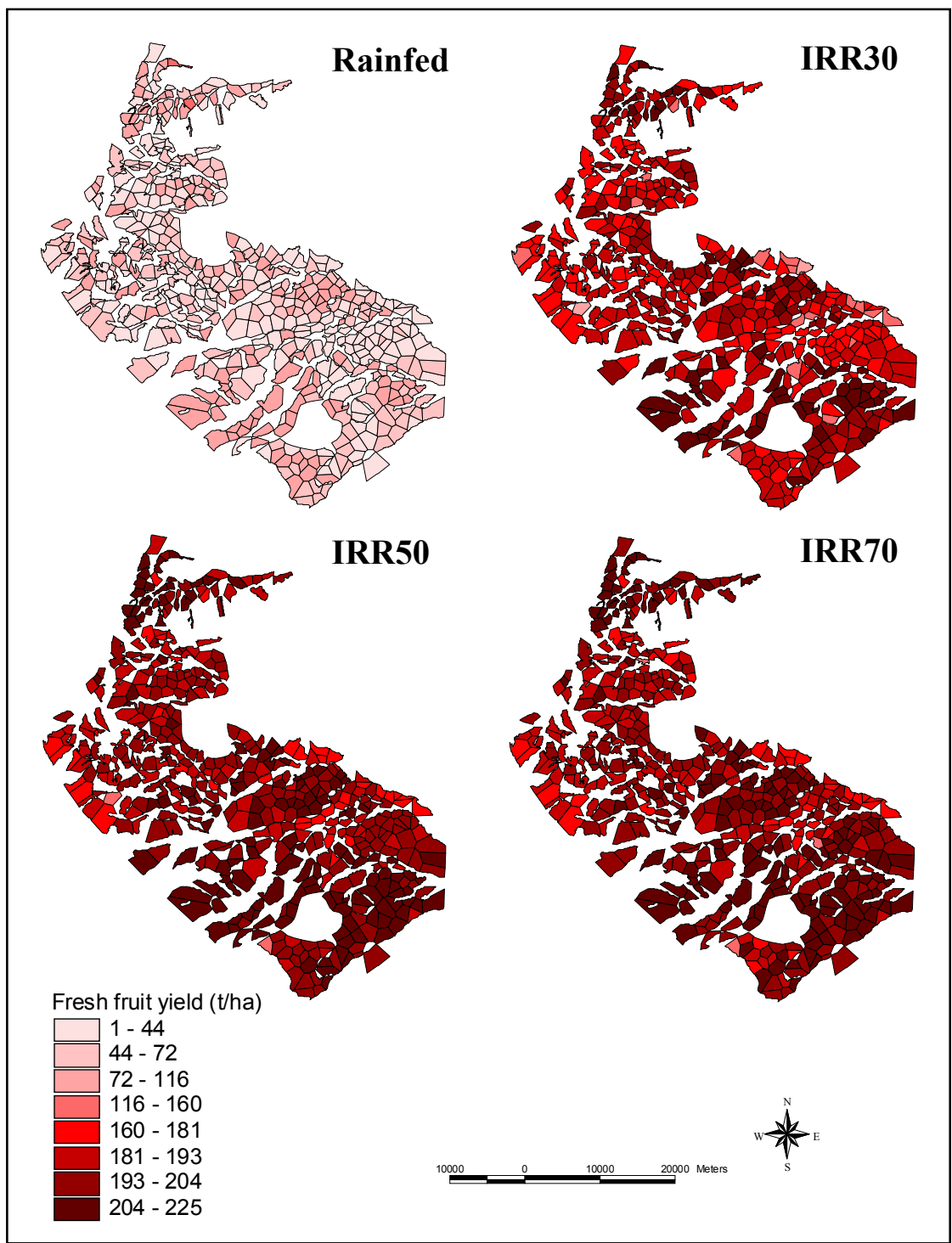

Figure 4: Fresh fruit yield $\left(\mathrm{t} \mathrm{ha}^{-1}\right)$ of processing tomato simulated by CROPGRO model in the four irrigation scenarios and mapped for the 481 soil polygons. 


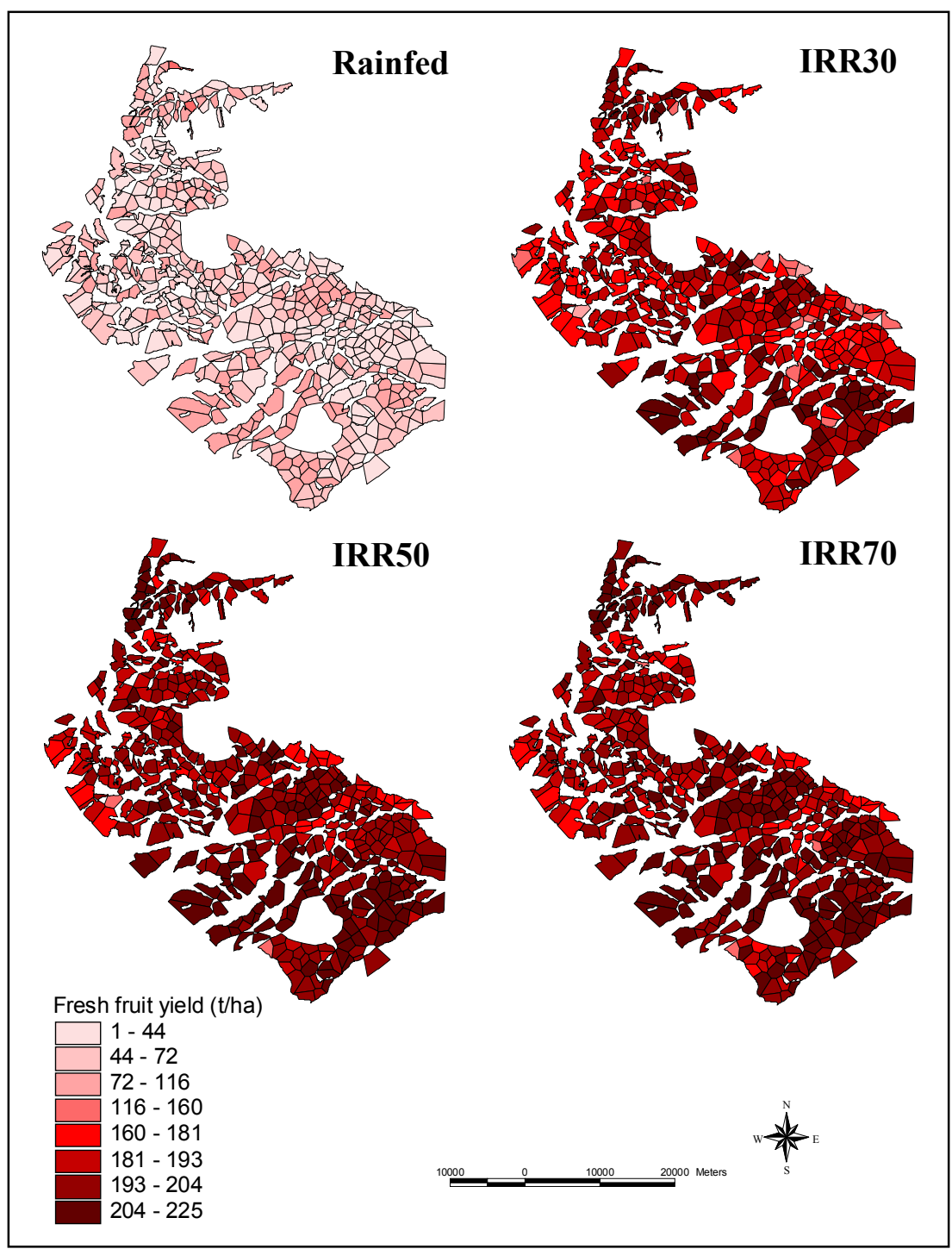

Figure 5: Net return $\left(€ \mathrm{ha}^{-1}\right)$ of processing tomato simulated by CERESWheat model in the four irrigation scenarios and mapped for the 481 soil polygons.

Fresh fruit yields in the irrigated scenarios were generally higher than those usually recorded in the test area (from 50 to $150 \mathrm{t} \mathrm{ha}^{-1}$ ), but this overestimation is explained because the model does not consider the effect of pest damages and weed competition. The fruit yield of rainfed scenario was very low, $54 \mathrm{t} \mathrm{ha}^{-1}$ on 
average and with a very large variability (Table 2), depending by rainfall, erratic in test area during the crop grown period (May-August). The irrigation stabilized the yield and few differences among the soils were noticed: a light superiority was observed in the areas close to LES station and in the southern part (Fig. 4). In the first case the effect is due to mitigation of the climate (especially during the summer) due to lake and sea proximity and to the richness in organic matter of the alluvial soils; in the second case the hydrological soil characteristics, mainly a greater CSW (Fig. 1), allowed a better tomato yield level and stability.

The effect of irrigation resulted in general the same in the area (Fig. 4) and was markedly evident, with fresh fruit yield three times greater than rainfed scenario. Further, the yearly variability of fruit yield was reduced with irrigation application with a lower standard deviation in irrigated crop (Table 2).

The different irrigation scenarios highlighted a variation in the irrigation volume and number of irrigation supplies, but not in fresh fruit yield, quite uniform among the scenarios and in the 481 soils (Fig. 4).

Economic analysis highlighted the significant advantage of irrigation in tomato crop, with a significant increase of NR (on average $+7800 € \mathrm{ha}^{-1}$ than rainfed) and a reduction of its variability (Table 2); the large profitability derived by a clear yield increase due to irrigation, also at the lowest CAW value, according to other simulations carried out in the same area [13]. The rainfed scenario is not too suggestible, because it showed negative NR in the totality of the years and in more than $80 \%$ of the soils. The incidence of irrigation in tomato production cost is low $(7 \div 10 \%$ of total cost) and for this reason the NR followed the yield spatial variability, depending largely by productivity.

\section{Conclusions}

Spatial and temporal analyses have been carried out to visualize the most productive and profitable pedo-climatic areas for wheat and tomato crops, when submitted to different irrigation scenarios. DSSAT models, coupled with AEGIS/WIN, allowed one to run long-term simulation and check the locations where the two crops give higher yields and net returns.

The climatic conditions (elevation and sea influence) and soil hydrological characteristics (mainly soil crop available water) influenced crop productivity, especially in wheat. The irrigation scenarios revealed a minimum effect of irrigation on durum wheat $(+19 \%)$ with no difference among irrigation scenarios. The simulated rainfed scenario productivity matched well with local averages yield and the areas more yielding resulted the central and northern ones.

The conclusion for wheat in the test area is that irrigated wheat is not convenient for the high cost of water and labour and for the low price of product. In fact, the incidence of irrigation cost is higher than tomato and ranges from $35 \%$ (IRR10) to 52\% (IRR50). Rainfed wheat is a low profit crop management, but important in the farms adopting a rotation with irrigated crops, to allow a positive (agronomic) sequence of different crops on the same land.

The simulation of processing tomato showed a very low productivity in rainfed scenario and high yield in irrigation treatments also at CAW 30\%. 
The two crops highlighted different responses to irrigation practice: for the wheat the increasing of grain yield respect to rainfed was not enough to compensate the irrigation cost. On the contrary, irrigation in tomato increased three times fruit yield than rainfed scenario, showing a positive net return (NR > $\left.5000 € \mathrm{ha}^{-1}\right)$. The soil-climate characteristics influenced mainly wheat response and less tomato yield, because this latter is more dependent by irrigation water than rainfall.

Further development of this research will be the application of geostatistical analysis to obtain larger homogenous areas and the checking of vulnerable areas for environmental aspects (leaching, pollution, drought, desertification) using improved simulation models. In the future, this kind of decision support systems could be used by stakeholders to plan agricultural land use and water distribution, simulating water requirement and crop yield at regional level.

\section{Acknowledgements}

This work is supported by Italian Ministry of Agriculture and Forestry Policies under contract n. 209/7393/05 (AQUATER Project).

\section{References}

[1] Penning de Vries, F.W.T., Jansen, D.M., ten Berge, H.F.M. \& Bakema, A., Simulation of ecophysiological processes of growth in several annual crops. Pudoc, Simulation Monographs 29: Wageningen, The Netherlands, pp. 271, 1989.

[2] Dent, J.B. \& Thornton, P.K., The role of Biological Simulation Models in Farming Systems Research. Agricultural Administration and Extension, 29, pp. 111-122, 1988.

[3] Hartkamp, A.D., White, J.W. \& Hoogenboom, G., Interfacing geographic information systems with agronomic modelling. A review. Agronomy Journal, 91, pp. 761-772, 1999.

[4] Hoogenboom, G. \& Thornton, P.K., A GIS for agrotechnology transfer in Guatemala. Proc. Application of Geographic Information System, Simulation Models, and Knowledge-based Systems for land use management, Blacksburg, VA. 12-14 Nov. 1990. Va. Polytechnic Inst. \& State Univ., Blacksburg, pp. 61-70, 1990.

[5] Thornton, P.K., Saka, A.R., Singh, U., Kumwenda, J.D.T., Brink, J.E. \& Brisson, N., Application of a maize crop simulation model in the central region of Malawi. Experimental Agriculture, 31, pp. 213-226, 1995.

[6] Calixte, J.P., Beinroth, F.H., Jones, J.W. \& Lal, H., Linking DSSAT to a GIS. Agrotechnology Transfer, 15, pp. 1-7, 1992.

[7] Georgiev, G.A., Hoogenboom, G. \& Ragupathy, K., Regional yield estimation using a linked geographic information system, crop application of crop models and GIS. Agronomy abstracts Biol. Eng., $1^{\text {st }}$ IBE Publ., Athens, GA, p. 63, 1998. 
[8] Heinemann, A.B., Hoogenboom, G. \& de Faria, R.T., Determination of spatial water requirements at county and regional levels using crop models and GIS. An example for the State of Parana, Brazil. Agricultural Water Management, 52, pp. 177-196, 2002.

[9] Batchelor, W.D., Basso, B. \& Paz, J.O., Examples of strategies to analyze spatial and temporal variability using crop models. European Journal of Agronomy, 18, pp. 141-158, 2002.

[10] Nijbroek, R., Hoogenboom, G. \& Jones, J.W., Optimizing irrigation management for a spatially variable soybean field. Agricultural Systems, 76, pp. 359-377, 2003.

[11] Rinaldi, M., Flagella, Z. \& Losavio, N., Evaluation and application of the OILCROP-SUN model for sunflower in southern Italy. Agricultural Systems, 78, pp. 17-30, 2003.

[12] Rinaldi, M., Water availability at sowing and nitrogen management of durum wheat: a seasonal analysis with CERES-Wheat model. Field Crops Research, 89, pp. 27-37, 2004.

[13] Rinaldi, M., Ventrella, D. \& Gagliano, C., Comparison of nitrogen and irrigation strategies in tomato using CROPGRO model. A case study from Southern Italy. Agricultural Water Management, 87, pp. 91-105, 2007.

[14] Thornton, P.K., \& Hoogenboom, G., A computer program to analyze single-season crop model outputs. Agronomy Journal, 86(5), pp. 860-868, 1994.

[15] Jones, J.W., Hoogenboom, G., Porter, C.H., Boote, K.J., Batchelor, W.D., Hunt, L.A., Wilkens, P.W., Singh, U., Gijsman, A.J. \& Ritchie, J.T., The DSSAT cropping system model. European Journal of Agronomy, 18, pp. 235-265, 2003.

[16] Rinaldi, M., Durum wheat simulation in Southern Italy using CERESWheat model. I. Calibration and validation. Proc. of $2^{\text {nd }}$ International Symposium "Modelling Cropping Systems": Florence (Italy), 16-18 July, pp. 81-82, 2001.

[17] Hartkamp, A.D., de Beurs, K., Stein, A. \& White, J.W., Interpolation techniques for climate variables, NRG-GIS Series 99-01. CIMMyt, Mexico, DF., 1999.

[18] Engel, T., Hoogenboom, G., James, W.J. \& Paul, W.W., AEGIS/WIN: A computer program for the application of crop simulation models across geographic areas. Agronomy Journal, 89, pp. 919-928, 1997. 